\title{
Inverter 5-Tingkat Tiga Fasa Empat Kawat menggunakan STM32F407 untuk Catu Daya Mandiri
}

\author{
IVANILES PUTRA UTAMA DAGOMIS, LEONARDUS HERU PRATOMO
}

\author{
Universitas Katolik Soegijapranata Semarang, Indonesia \\ Email: ivanilesputra14@gmail.com
}

Received 26 Agustus 2020 | Revised 22 September 2020 | Accepted 30 September 2020

\begin{abstract}
ABSTRAK
Salah satu energi terbarukan adalah pembangkit listrik tenaga surya (PLTS), yang menggunakan photovoltaic (PV) sebagai sarana konversi energi. Untuk mendapatkan daya maksimal, menggunakan konverter DC-DC beralgoritma maximum power point tracker (MPPT). Sistem di Indonesia menggunakan tiga fasa empat kawat (TFEK), sehingga sistem perlu diintegrasi menjadi satu, dikenal dengan nama konversi dua tahap. Masalah yang muncul adalah konverter TFEK lazim diimplementasi menggunakan konverter daya empat lengan, di mana setiap lengannya terdapat dua buah sakelar daya. Hal ini akan mengakibatkan sistem pensaklaran yang tinggi, tapis dan stress tegangan yang besar untuk mendapatkan THD rendah. Oleh karena itu, telah diteliti inverter TFEK menggunakan 5-level inverter. Metode modulasi lebar pulsa digital sinusoidal (MLPDS) digunakan untuk mengendalikan setiap sakelar (IRFP 460) dengan menggunakan mikrokontrol jenis STM32F407. Verifikasi menggunakan perangkat lunak PSIM dan prototype. Berdasarkan hasil pengujian, metode yang dilakukan mampu menghasilkan arus dan tegangan keluaran inverter TFEK dengan THD tegangan sebesar 4,38\%.
\end{abstract}

Kata kunci: Inverter 5-tingkat, Tiga fasa empat kawat, STM32F407, THD

\begin{abstract}
One of the renewable energy is solar power plant (PLTS), which uses photovoltaic $(P V)$ as a means of energy conversion. To get maximum power, use a DC-DC converter with a maximum power point tracker (MPPT). The system in Indonesia uses three-phase four-wires (TPFW), the system needs to be integrated into one, as two-stage conversion. The problem is that TPFW converters are commonly implemented using four-leg power converter, where each leg has two power switches. This will result in high switching system, large filters, and stress voltage to get low THD. Hence, the TPFW inverter 5-level inverter has been investigated. The sinusoidal pulse width modulation (SPWM) method is used to control each switch (IRFP 460) using an STM32F407 microcontroller. Verification with PSIM software and prototype. Based on the results, the method used can produce the current and output voltage of the TPFW inverter with a voltage THD of $4.38 \%$.
\end{abstract}

Keywords: five-level inverter, three-phase four-wire, STM32F407, THD 
Ivaniles Putra Utama Dagomis, Leonardus Heru Pratomo

\section{PENDAHULUAN}

Energi listrik sangatlah penting dalam kehidupan sehari-hari. Dengan meningkatnya jumlah penduduk dan kemajuan teknologi dari tahun ke tahun, keperluan distribusi listrik yang stabil dan merata menjadi sangat penting (Hakim, dkk, 2018). Di beberapa negara berkembang distribusi listrik sangatlah tinggi, karena permintaan pengguna listrik semakin banyak (Wilson, dkk, 2016). Semakin banyak permintaan pengguna listrik energi yang dihasilkan semakin meningkat pula. Pembangkit listrik dirancang berdasarkan sumber energi yang ada pada lokasi geografis (Ardin, dkk, 2017). Banyak generator pembangkit listrik yang memiliki dampak, seperti pembangkit listrik tenaga uap (PLTU). Sisa gas buang dari pembangkit listrik termasuk dalam polusi udara yang utama (Tran, dkk, 2017).

Pembangkit listrik tenaga surya (PLTS) dapati di semua tempat, dikarenakan pembangkit listrik ini hanya memerlukan energi radiasi matahari. Di beberapa tempat yang tertinggal, distribusi listrik tidak merata, dengan menggunakan photovoltaic (PV) kebutuhan listrik dapat tercukupi (Sanadeera, dkk, 2015). Panel surya mengubah radiasi matahari menjadi listrik, hasil listrik yang dihasilkan adalah arus listrik searah. Oleh karena itu untuk membuat arus selalu maksimal memerlukan konverter daya yang beragoritma kurva maksimal (Pratomo, dkk, 2020). Agar arus dari PV dapat digunakan diperlukan pengubah arus. Pengubah arus searah dari PV menjadi arus bolak-balik memerlukan rangkaian daya yang di sebut inverter (Pratomo, dkk, 2015) (Pratomo, dkk, 2020). Inverter memiliki banyak jenis pensaklaran, seperti unipolar, bipolar (Hamid, dkk, 2019). Inverter pada umumnya memiliki dua jenis Voltage Source Inverter (VSI) dan Current Source Inverter (CSI) (Neukirchner, dkk, 2017). Selain dua jenis itu inverter memiliki topologi yang berbeda-beda baik satu fasa maupun tiga fasa (Rahman, dkk, 2016) Inverter tiga fasa umumnya menggunakan tiga buah lengan (Trivedi, dkk, 2016) (Rahman, dkk, 2016) sehingga lebih sering munculnya stress tegangan. Karena bekerja pada frekuensi tinggi sehingga membutuhkan tapis induktor yang besar. Pada umumnya kelisitrikan di Indonesia menggunakan sistem tiga fasa empat kawat. Masalahnya penggunaan inverter dalam pembangkit mandiri, inverter tiga fasa empat kawat konvensional memerlukan frekuensi tinggi, tapis daya yang besar untuk mendapatkan nilai Total Harmonic Distortion (THD), sehingga dengan menggunakan inverter 5 -tingkat tiga fasa empat kawat (TFEK) hanya menggunakan frekuensi yang rendah dan tapis yang kecil untuk mendapatkan THD yang rendah. Standart THD yang gunakan yaitu standart THD IEE dengan nilai harmonik 5\% untuk tegangan 2.3-69kV (IEEE Recommended Practice and Requirements for Harmonic Control in Electric Power Systems, 2014).

Tujuan dari penelitian ini adalah memberi solusi untuk menghasilkan sinyal keluaran inverter TFEK dengan tapis induktor yang kecil sehingga inverter lebih sederhana. Dengan menghubungkan menggunakan konverter berbasis Maxmimun Power Point Tracker (MPPT) daya yang dihasilkan dari PV selalu maksimal. Langkah kedua menggunakan inverter sebagai pengkonversi arus searah ke arus bolak-balik. Dengan menggunakan inverter 5 -tingkat TFEK pada aplikasi off grid inverter hanya memerlukan tapis yang kecil. Pengimplementasi perangkat keras sistem menggunakan mikrokontroller STM32F407. Sebagai tahap awal penelitian membahas prinsip kerja inverter 5-tingkat off grid dan pada bagian kedua dari jurnal ini membahas prinsip kerja dari inverter 5-tingkat TFEK. Untuk Simulasi, implementasi dan pembahasan ada di bagian tiga. 


\section{METODE PENELITIAN}

PLTS mandiri menggunakan dua tahap konversi, dari PV dimaksimalkan dengan konverter berbais algortima MPPT menjadi arus searah kemudian di ubah menjadi arus bolak balik seperti Gambar 1. Pada umumnya kelisitrikan di Indonesia menggunakan sistem tiga fasa empat kawat. Pada prinsipnya inverter 5-tingkat TFEK terdiri dari tiga buah inverter 5-tingkat yang di susun secara paralel. Sehingga memiliki tiga fasa yang masing-masing bergeser $120^{\circ}$ dan memiliki kabel netral.

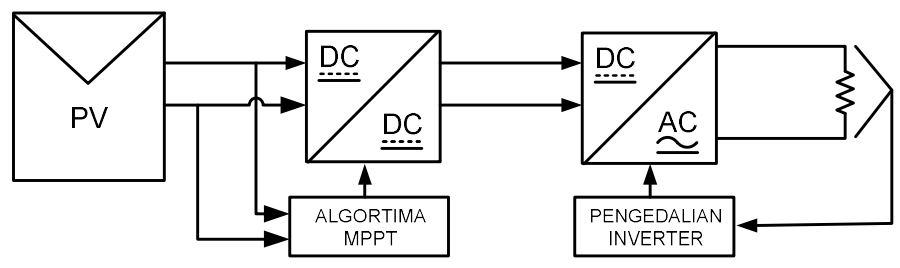

\section{Gambar 1. PLTS Dua Tahap Konversi}

Penelitian ini menggunakan metode seperti diagram alir yang ditunjukkan pada Gambar 2. Pertama mengkaji pengaturan inverter 5-tingkat TFEK sebagai pembentuk gelombang sinusiudal. Dengan menggunakan metode satu panjang gelombang sebagai acuan pembentuk gelombang keluaran tiap fasa menggunakan STM32F407. Setelah itu merumuskan masalah yang ada dan membuat simulasi untuk mengatasi hal tersebut. Verifikasi dilakukan dengan implementasi perangkat keras serta melakukan pegujian dan pengambilan data. Pada bagian terakir membuat kesimpulan mengenai masalah yang ada.

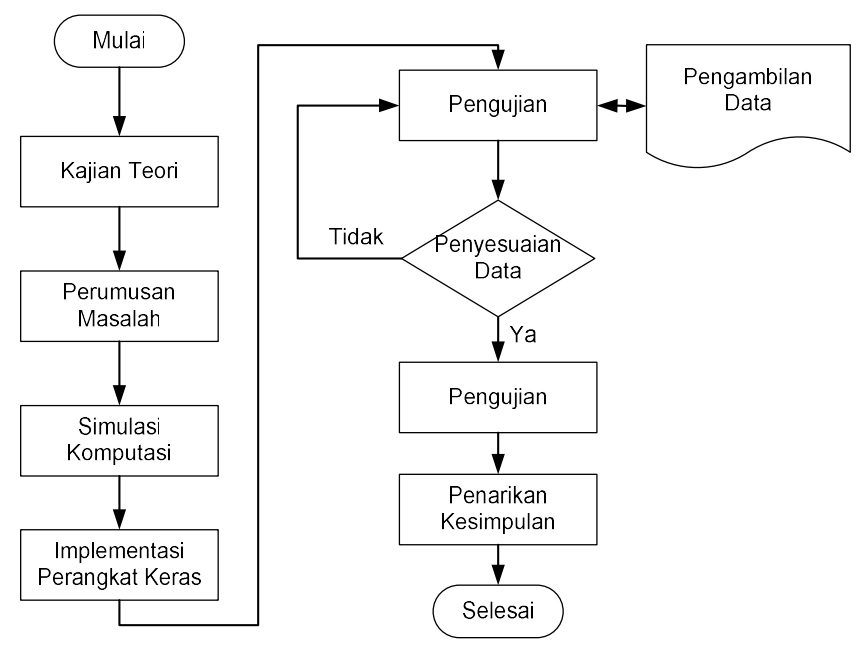

Gambar 2. Flow Chart Metode Penelitian

\subsection{Inverter 5-Tingkat}

Pada prinsipnya inverter 5-tingkat yang digunakan merupakan hasil modifikasi dari inverter Full-Bridge. Inverter Full-Bridge memiliki empat buah sakelar daya yang beroperasi pada pengaplikasian daya besar (Hamid, dkk, 2019). Keempat buah sakelar daya dalam Inverter Full-bridge dapat di kendalikan secara bipolar maupun unipolar (Algaddafi, dkk, 2017) (Hamid, dkk, 2019) (Maheshri, dkk, 2014). Topologi Inverter 5-Tingkat yang digunakan seperti pada Gambar 3. 


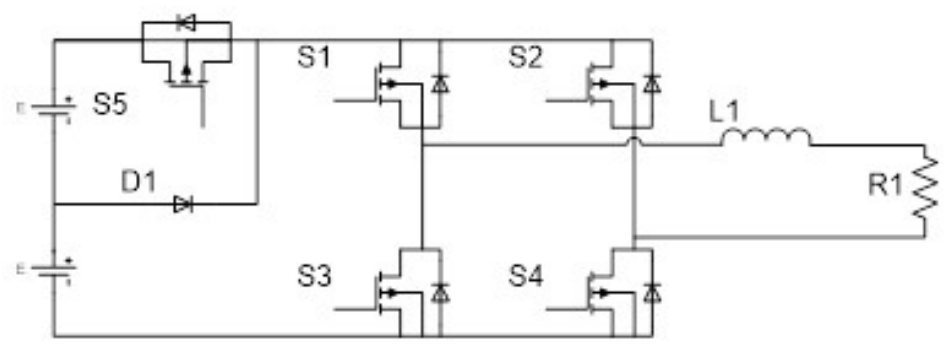

Gambar 3. Topologi Inverter 5-tingkat

Prinsip kerja inverter 5-tingkat dibagi menjadi 5 mode operasi termasuk mode freewheeling:

1. Mode Operasi 1

Ketika sakelar daya S1 dan D1 konduktansi maka arus dari sumber DC (E) akan mengalir ke beban dan kembali ke sumber DC (E) sakelar daya S4. Gambar 4 menunjukan mode operasi pertama. Model matematika dari mode operasi ini ditunjukkan pada Persamaan (1).

$$
\begin{aligned}
& E=v_{L}+V_{o} \\
& E=L \frac{d i_{L}}{d t}+V_{o}
\end{aligned}
$$

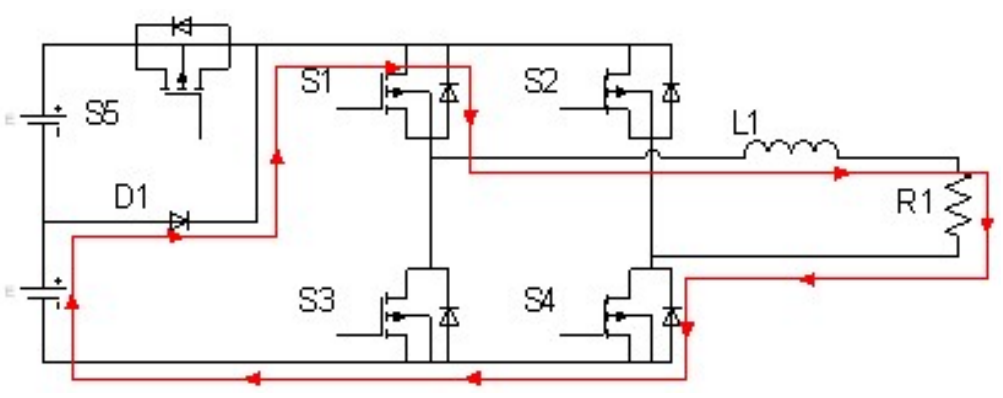

Gambar 4. Mode Operasi Satu

2. Mode Operasi 2

Ketika sakelar daya S5 dan S1 konduktansi maka arus dari sumber DC (E+E) akan mengalir ke beban dan kembali ke sumber DC (E+E) melalui sakelar daya S4. Gambar 5 menunjukkan mode operasi kedua. Model matematika dari mode operasi ini ditunnjukkan pada Persamaan (2).

$$
\begin{gathered}
E+E=v_{L}+V_{o} \\
2 E=L \frac{d i_{L}}{d t}+V_{o}
\end{gathered}
$$




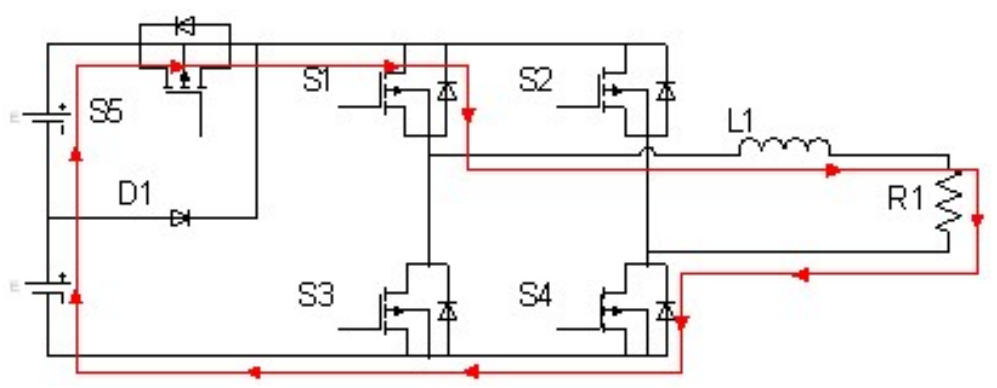

Gambar 5. Mode Operasi Dua

3. Mode Operasi 3

Ketika sakelar daya S1 dan S2 konduktansi, arus freewheeling mengalir ke beban dengan nilai positif dan jika kombinasi sakelar daya S3 dan S4 konduktansi akan menghasilkan arus dengan nilai negatif. Gambar 6 menunjukkan mode operasi ketiga. Model matematika dari mode operasi ini ditunjukkan pada Persamaan (3).

$$
\begin{gathered}
v_{L}=V_{o}-v_{d} \\
L \frac{d i_{L}}{d t}=V_{o}-0 \\
V_{o}=L \frac{d i_{L}}{d t}
\end{gathered}
$$

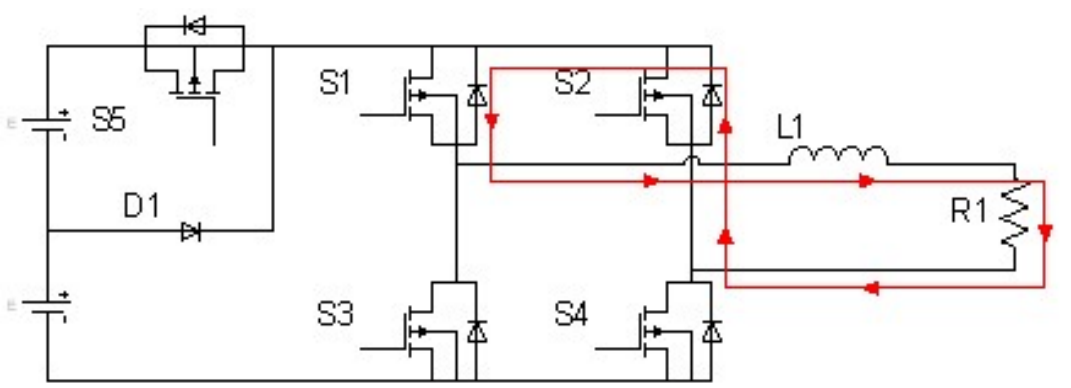

(a)

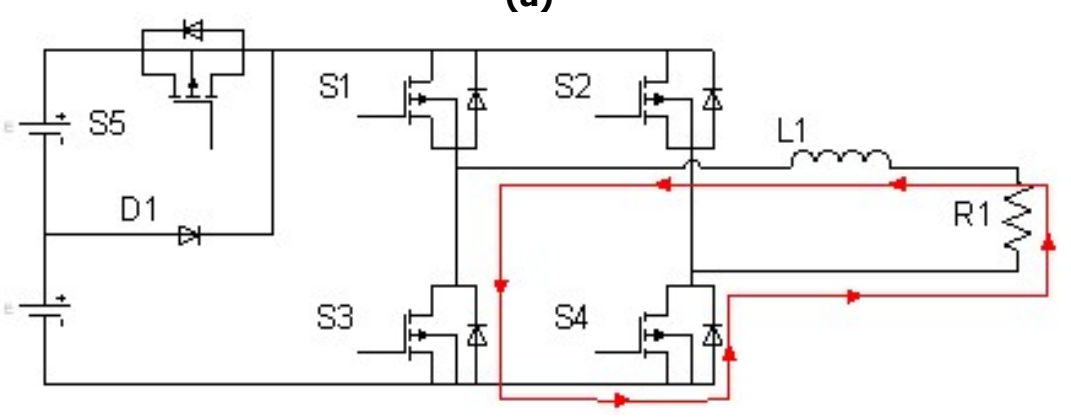

(b)

Gambar 6. (a) Freewheeling positif (b) Freewheeling negatif 
4. Mode Operasi 4

Ketika D1 dan sakelar daya S1 konduktansi maka arus dari sumber DC (E) akan mengalir ke beban dan Kembali ke sumber DC (E) melalui sakelar daya S3. Gambar 7 menunjukan mode operasi kempat. Model matematika dari mode operasi ini ditunjukkan pada Persamaan (4).

$$
\begin{aligned}
& -E=v_{L}+V_{o} \\
& -E=L \frac{d i_{L}}{d t}+V_{o}
\end{aligned}
$$

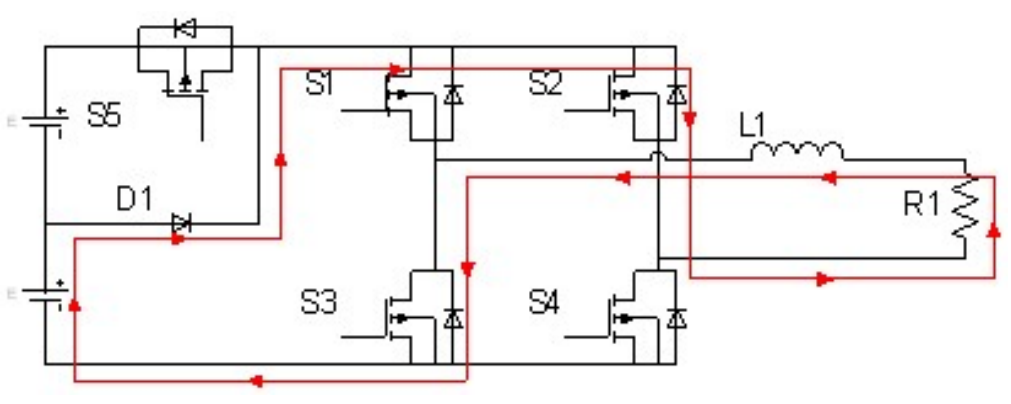

Gambar 7. Mode Operasi Empat

5. Mode Operasi 5

Ketika sakelar daya S5 dan S2 konduktansi maka arus dari sumber DC (E+E) akan mengalir ke beban dan Kembali ke sumber DC (E+E) melalui sakelar daya S3. Gambar 8 menunjukkan mode operasi kempat. Model matematika dari mode operasi ini ditunjukkan pada Persamaan (5).

$$
\begin{gathered}
-(E+E)=v_{L}+V_{o} \\
-2 E=L \frac{d i_{L}}{d t}+V_{o}
\end{gathered}
$$

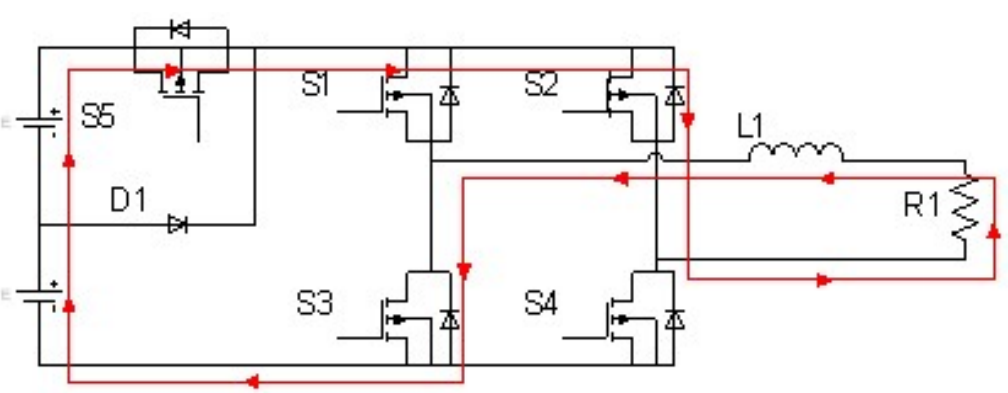

Gambar 8. Mode Operasi Lima

Mode operasi (1-5), polaritas pensaklaran selalu $50 \mathrm{~Hz}$ untuk menghasilkan setengah siklus positif dan setengah siklus negatif. Logika pensaklaran dari mode oprasi (1-5) ditunjukkan dalam Tabel 1. 
Tabel 1. Konfigurasi Pensaklaran 5-Tingkat

\begin{tabular}{|c|c|c|c|c|c|}
\hline \multicolumn{2}{|c|}{$\begin{array}{c}\text { Pembentu } \\
\text { k Polaritas }\end{array}$} & \multicolumn{3}{|c|}{$\begin{array}{c}\text { Pembentuk } \\
\text { Level }\end{array}$} & \multirow{2}{*}{$\begin{array}{c}\text { Tegangan } \\
\text { Keluaran }\end{array}$} \\
\hline S2 & $\boldsymbol{S 4}$ & $\boldsymbol{S 1}$ & $\boldsymbol{S 3}$ & $\boldsymbol{S 5}$ & \\
\hline 0 & 1 & 1 & 0 & 0 & $\mathrm{E}$ \\
\hline 0 & 1 & 1 & 0 & 1 & $2 \mathrm{E}$ \\
\hline 1 & 0 & 1 & 0 & 0 & 0 \\
\hline 0 & 1 & 0 & 1 & 0 & 0 \\
\hline 1 & 0 & 0 & 1 & 1 & $-2 \mathrm{E}$ \\
\hline 1 & 0 & 0 & 1 & 0 & $-\mathrm{E}$ \\
\hline
\end{tabular}

\subsection{Inverter 5-Tingkat Tiga Fasa Empat Kawat (TFEK)}

Topologi Inverter 5-Tingkat Tiga Fasa Empat Kawat (TFEK) ditunjukkan pada Gambar 9. Inverter 5-Tingkat Tiga Fasa Empat Kawat (TFEK) ini memiliki kontruksi yang terdiri dari tiga buah inverter 5 -tingkat.

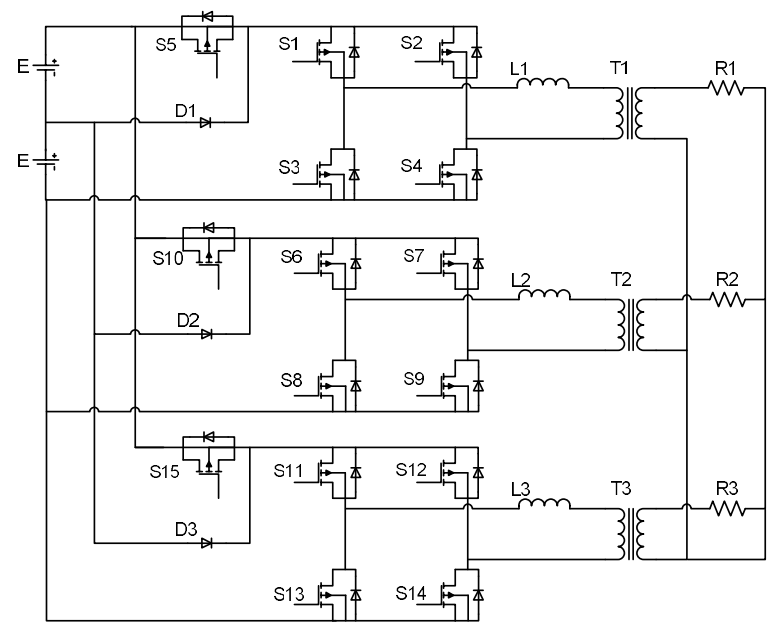

Gambar 9. Topologi Inverter 5-Tingkat Tiga Fasa Empat Kawat

Trafo yang digunakan memiliki dua lilitan, lilitan primer, dan lilitan sekunder. Berdasarkan jumlah perbandingan antara lilitan sekunder dan lilitan primer, dapat menentukan tegangan primer dan tegangan sekunder pada trafo. Untuk menentukan nilai lilitan dan tegangan trafo di tunjukan dengan Persamaan (6).

$$
\frac{N_{p}}{N_{s}}=\frac{V_{p}}{V_{s}}
$$

$$
\begin{aligned}
& \mathrm{N}_{1}=\text { Jumlah Lilitan Primer } \\
& \mathrm{N}_{2}=\text { Jumlah Lilitan Sekunder } \\
& \mathrm{V}_{\mathrm{p}}=\text { Tegangan Primer } \\
& \mathrm{V}_{\mathrm{s}}=\text { Tegangan Sekunder }
\end{aligned}
$$

Pada Gambar 9 masing - masing inverter memiliki arus keluaran dengan pergeseran sudut sebesar 120 derajat. Pada sisi kelauran inverter agar setiap fasa terhubung, menggunakan sisi primer trafo (T1, T2, dan T3) dan pada keluaran sisi sekunder trafo di hubungkan dengan rangkaian Wye. Sisi sekunder trafo (T1) untuk fasa pertama yaitu 0 derajat, untuk fasa kedua 
yaitu 120 derajat pada sisi sekunder trafo (T2) dan untuk fasa ketiga yaitu 240 derajat pada sisi sekunder keluaran trafo (T3).

\subsection{Modulasi Lebar Pulsa Digital Sinusoidal (MLPDS)}

Pengendalian inverter dapat dilakukan dengan berbagai metode, pada umumnya inverter di kendalikan dengan metode on dan off sehingga arus keluaran berbentuk kotak (Ahmad, dkk, 2019). Agar keluaran inverter berbentuk sinusoidal maka di perlukan MLPDS untuk mengendalikan saklear daya. Gambar 10 menunjukan rangkaian komparator pembentuk MLPDS untuk inverter 5-Tingkat TFEK. Dengan membandingkan dua buah sinyal, yang berbentuk segitiga (carrier) dan sinyal refrensi yang berbentuk sinusoidal maka akan menghasilkan hasil sinyal keluaran MLPDS yang akan di gunakan untuk pensaklaran sakelar daya.
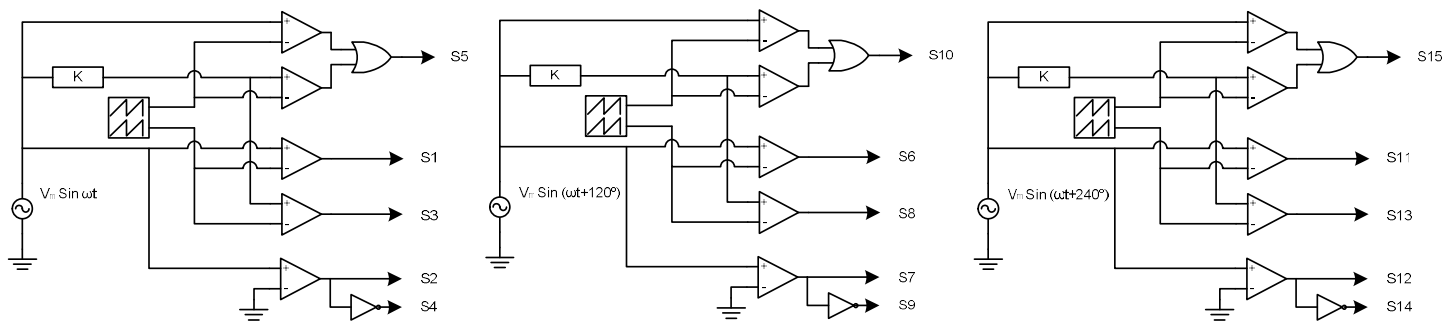

\section{Gambar 10. Rangkain Komparator Inverter 5-Tingkat TFEK}

\subsection{Algortima Pemprograman}

Pola pensaklaran MLPDS seperti pada Gambar 11. Pola ini menggunakan satu periode gelombang sinusoidal dengan periode 0.02 detik atau $50 \mathrm{~Hz}$ sebagai gelombang informasi yang akan digunakan untuk pensaklaran. Pada Gambar 12 S2 dan S4 digunakan sebagai pembentuk polaritas dan untuk mengurangi desipasi panas, karena memiliki waktu jeda disebut dengan one-leg control. Gambar 11 menunjukan pola pensakelaran dari satu fasa, maka dapat dibuat suatu diagram alir pemrograman seperti Gambar 12, untuk fasa kedua dan ketiga menggunakan metode yang sama, dengan pergeseran $120^{\circ}$.

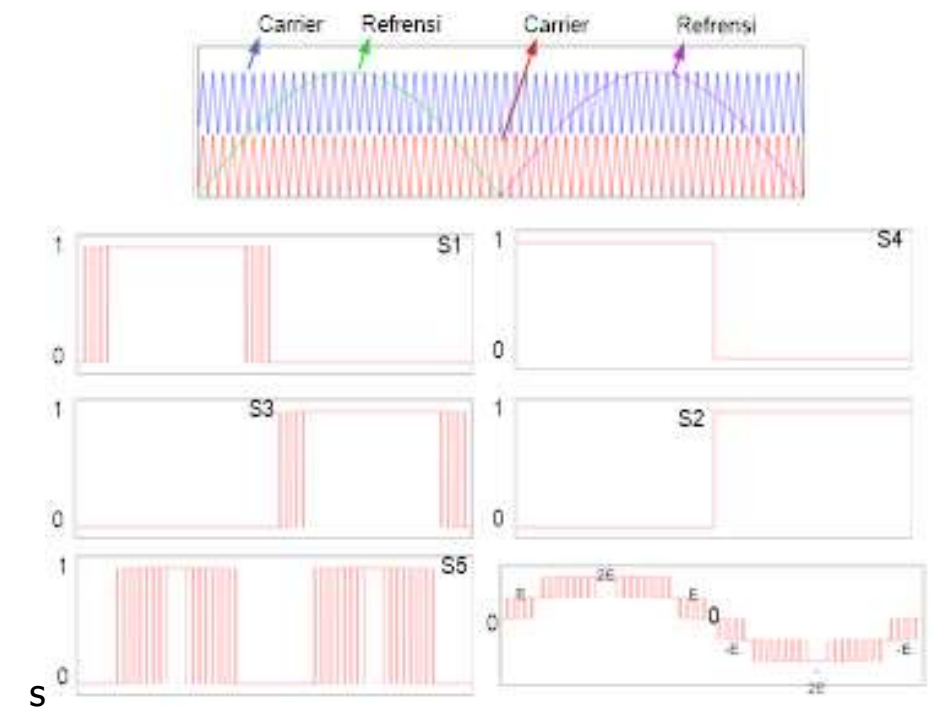

Gambar 11. Pola Pensakaran MLPDS 


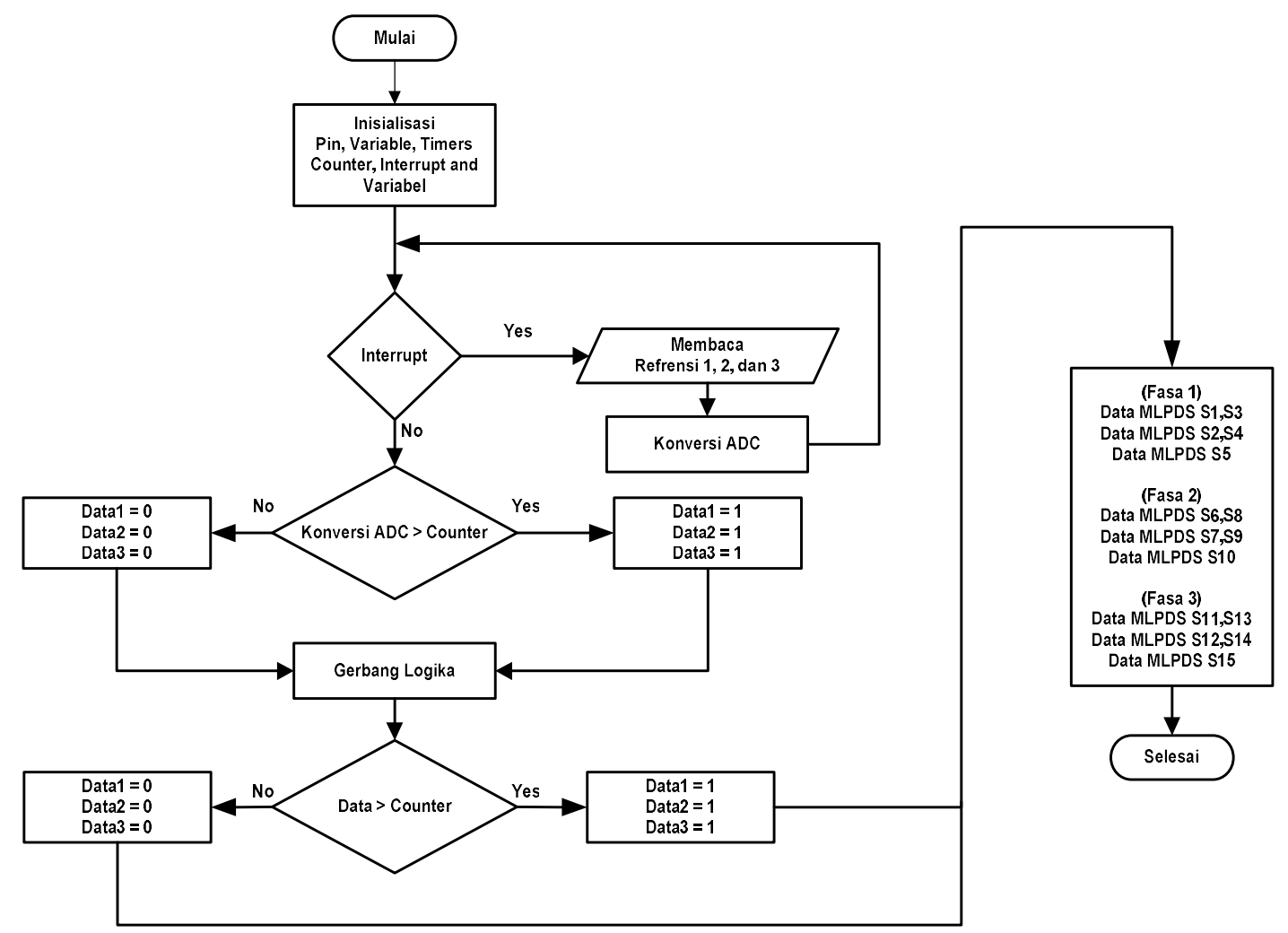

Gambar 12. Diagram Alir Pemrograman

Pada Gambar 12 menggunakan timer counter untuk menjalankan fungsi interrupt dan pembangkit sinyal carrier. Konsep pembangkit sinyal carrier menggunakan metode up counter dan down counter. Seperti Gambar 11 menggunakan dua buah sinyal carrier bertingkat hanya dengan menggunakan satu buah timer counter dapat menghasilkan dua buah carrier bertingkat. Pada mikrokontroller STM32F407 menggunakan tiga pin ADC yang di fungsikan sebagai pembacaan sinyal refrensi untuk dikomparasi. Hasil konversi nilai ADC digunakan sebagai sinyal refrensi yang nantinya akan dikomparasi dengan sinyal carrier yang menggunakan timer counter. Hasil komparator yang sudah dihubungkan dengan beberapa gerbang logika seperti Gambar 10 akan digunakan untuk pensaklaran sesuai dengan saklear daya. Pada algortima tersebut menggunakan 15 pin yang nantinya digunakan untuk mensaklar setiap sakelar sesuai dengan alur diagaram pemprograman yang akan menghasilkan sinyal keluaran inverter 5-Tingkat TFEK.

Program pada mikrokontroller tahap awal yang dilakukan adalah pendeklarasaian semua variabel sesuai dengan tipe data yang digunakan. Pengambilan data ADC dilakukan setiap $0.2 \mathrm{~ms}$ yang disimpan pada variable tipe data int. Pada bagian setup program dilakukan inisialisasi ADC, port, timer, dan sfinterrupt. Interrupt akan aktif ketika timer overflow dan ketika timer overflow akan membaca refrensi berupa ADC. Pada bagian looping program nilai $\mathrm{ADC}$ dibandingan dengan nilai counter dengan menggunakan perintah if else.

\subsection{Kontrol Boost Pengisian untuk MPPT}

Konverter Boost terintegrasi dengan MPPT untuk memaksimalkan daya keluaran PV ke baterai (Pratomo, dkk, 2019). Topologi boost converter ditunjukkan pada Gambar 13. Persamaan (7) menunjukan algoritma dari MPPT. 
Ivaniles Putra Utama Dagomis, Leonardus Heru Pratomo

$$
\left(\frac{d P}{d V}\right)_{M P P T}=0
$$

Berdasarkan pada Persamaan (7), sistem kontrol selalu berkerja seperti kondisi di bawah :

$$
\begin{aligned}
& \frac{d P}{d V}>0, \text { if } G>\Delta G \\
& \frac{d P}{d V}=0, \text { if } G=\Delta G \\
& \frac{d P}{d V}<0, \text { if } G<\Delta G
\end{aligned}
$$

Gambar 13 menunjukkan kurva karakteristik PV untuk MPPT yang ditujukkan untuk mengatur konverter yang seperti pada Gambar 14.

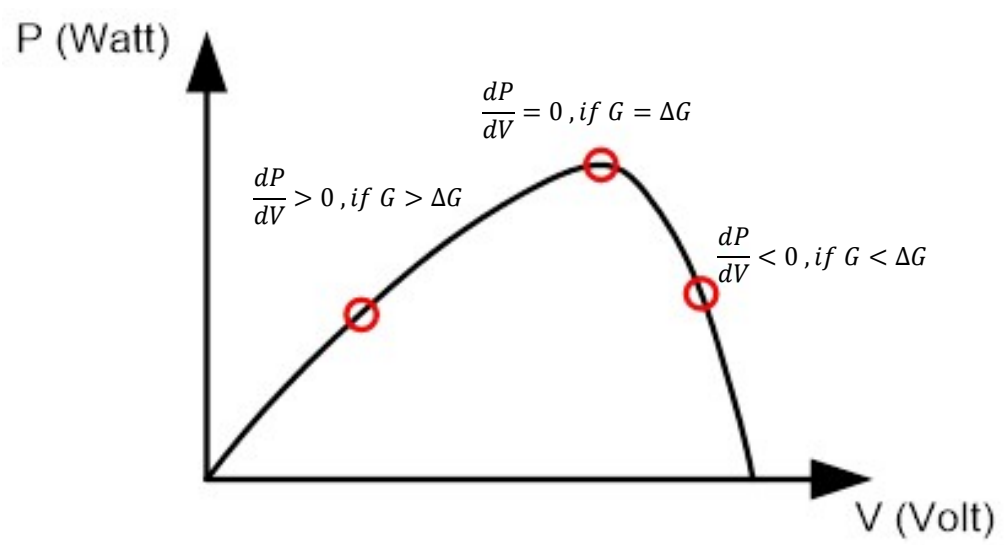

Gambar 13. Kurva Karakteristik PV

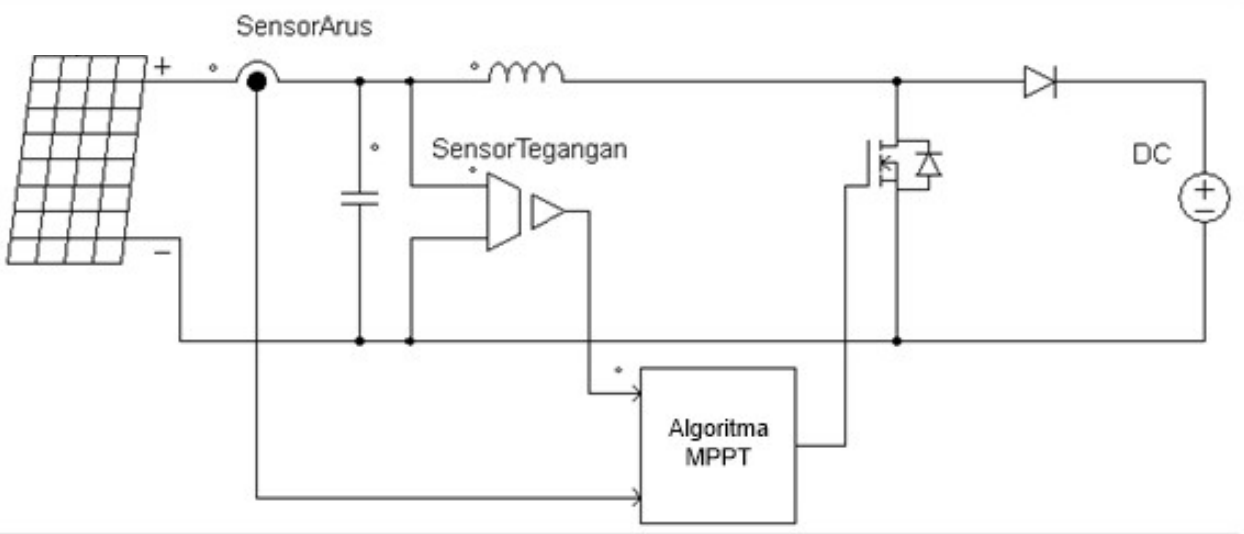

Gambar 14. Rangkaian Boost MPPT 


\section{HASL DAN PEMBAHASAN}

Berdasarkan pembahasan tentang mode operasi dapat diuraikan dalam bentuk simulasi komputasi dengan software Power Simulator (PSIM) dengan parameter seperti Tabel 2 dan dilakukkan implementasi perangkat keras dengan menggunakan parameter seperti Tabel 3.

Tabel 2. Parameter Simulasi

\begin{tabular}{|c|l|c|}
\hline No & \multicolumn{1}{|c|}{ Parameter } & Nilai \\
\hline 1 & Photovoltaic & $240 \mathrm{WP}$ \\
2 & Baterai & $74 \mathrm{Volt}$ \\
3 & Induktor & $6 \mathrm{mH}$ \\
4 & Beban & $24 \mathrm{Ohm}$ \\
5 & Trafo & $1: 1$ \\
\hline
\end{tabular}

Gambar 15 menunjukkan hasil simulasi daya keluaran dari konverter dengan algoritma MPPT menghasilkan daya selalu maksimal dengan menggunakan PV 120 WP. Dengan menggunakan dua buah MPPT sebagai sumber inverter 5 -tingkat TFEK dengan tapis inductor $2 \mathrm{mH}$ pada tiap fasa dan beban $8 \mathrm{Ohm}$. Gambar 17 (a). Memperlihatkan tegangan keluaran inverter sebelum tapis induktor. Gambar 18 (a). memperlihatkan tegangan setelah tapis induktor dan arus keluaran inverter pada salah satu fasa. Gambar 19 (a). menunjukkan hasil simulasi dengan tegangan 61 Volt pada setiap fasa. Gambar20 (a). menunjukkan arus keluaran tiap fasa dengan nilai 7.63 Ampere. Sudut $0^{\circ}$ ditunjukkan pada tegangan $R$ dan arus $R$, sudut $120^{\circ}$ ditunjukkan pada tegangan $S$ dan arus $S$, dan Sudut $240^{\circ}$ ditunjukkan pada tegangan $T$ dan arus $\mathrm{T}$.

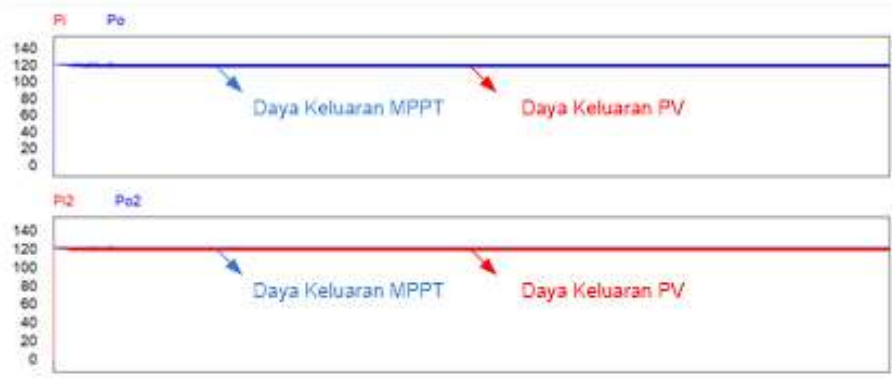

Gambar 15. Daya Keluaran PV dan MPPT

Tabel 3. Parameter Implementasi

\begin{tabular}{|c|l|c|}
\hline No & \multicolumn{1}{|c|}{ Parameter } & Nilai \\
\hline 1 & Tegangan DC (E) & 32 Volt \\
2 & Tegangan DC (E) & 32 Volt \\
3 & Induktor & $1 \mathrm{mH}$ \\
4 & Beban & $1200 \mathrm{Watt}$ \\
5 & Saklar & IRFP 460 \\
6 & Trafo step up & $1: 6,29$ \\
7 & Frekuensi Pensakalran & $5 \mathrm{KHz}$ \\
\hline
\end{tabular}

Dari parameter Tabel 3 merupakan parameter pengujian perangkat keras. Implementasi perangkat keras dilakukan guna membuktikan bahwa sistem yang dirancang dapat bekerja dengan baik. Implementasi menggunakan dua sumber $D C$ sebagai pemodelan dari keluaran 
MPPT. Penerapan perangkat keras dilakukan seperti Gambar 9 sedangkan Hasil penerapan perangkat keras dapat dilihat pada Gambar 16.

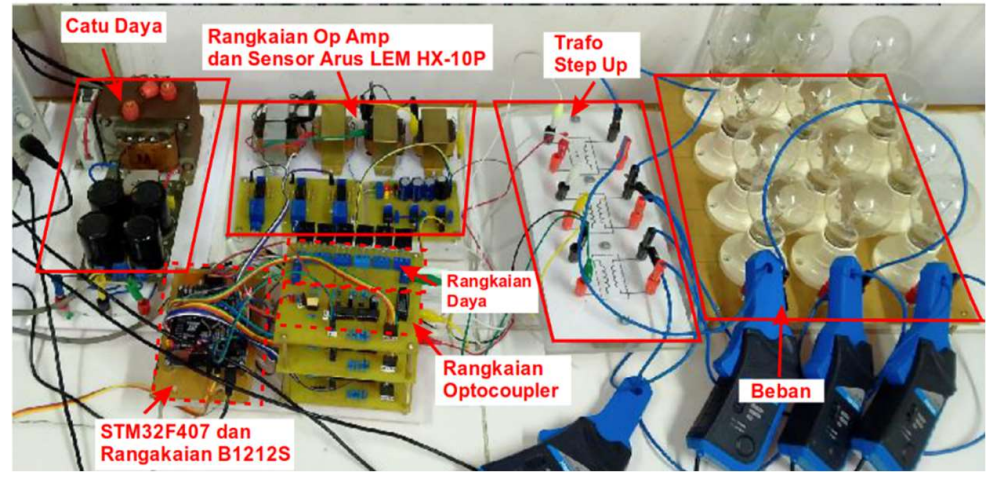

Gambar 16. Implementasi Perangkat Keras Inverter 5-Tingkat Tiga Fasa Empat Kawat

Berdasarkan diagram alir pemrograman seperti Gambar 12. Tegangan keluaran inverter sebelum tapis daya ditunjukkan pada Gambar 17 (b). Gambar 18 (b). menunjukkan keluaran arus dan tegangan inverter setelah tapis daya. Tegangan keluaran inverter setelah di step-up menggunakan trafo menghasilkan tegangan 200 VPP AC dengan beban 400 Watt. Dengan beban 400 Watt didapatkan arus sebesar 4 Ampere di setiap fasa dan arus netral yang bernilai mendekati 0 ampere. Sudut $0^{\circ}$ ditunjukan pada tegangan R dan arus R, sudut $120^{\circ}$ ditunjukkan pada tegangan $S$ dan arus $S$, dan Sudut $240^{\circ}$ ditunjukkan pada tegangan $T$ dan arus $\mathrm{T}$.
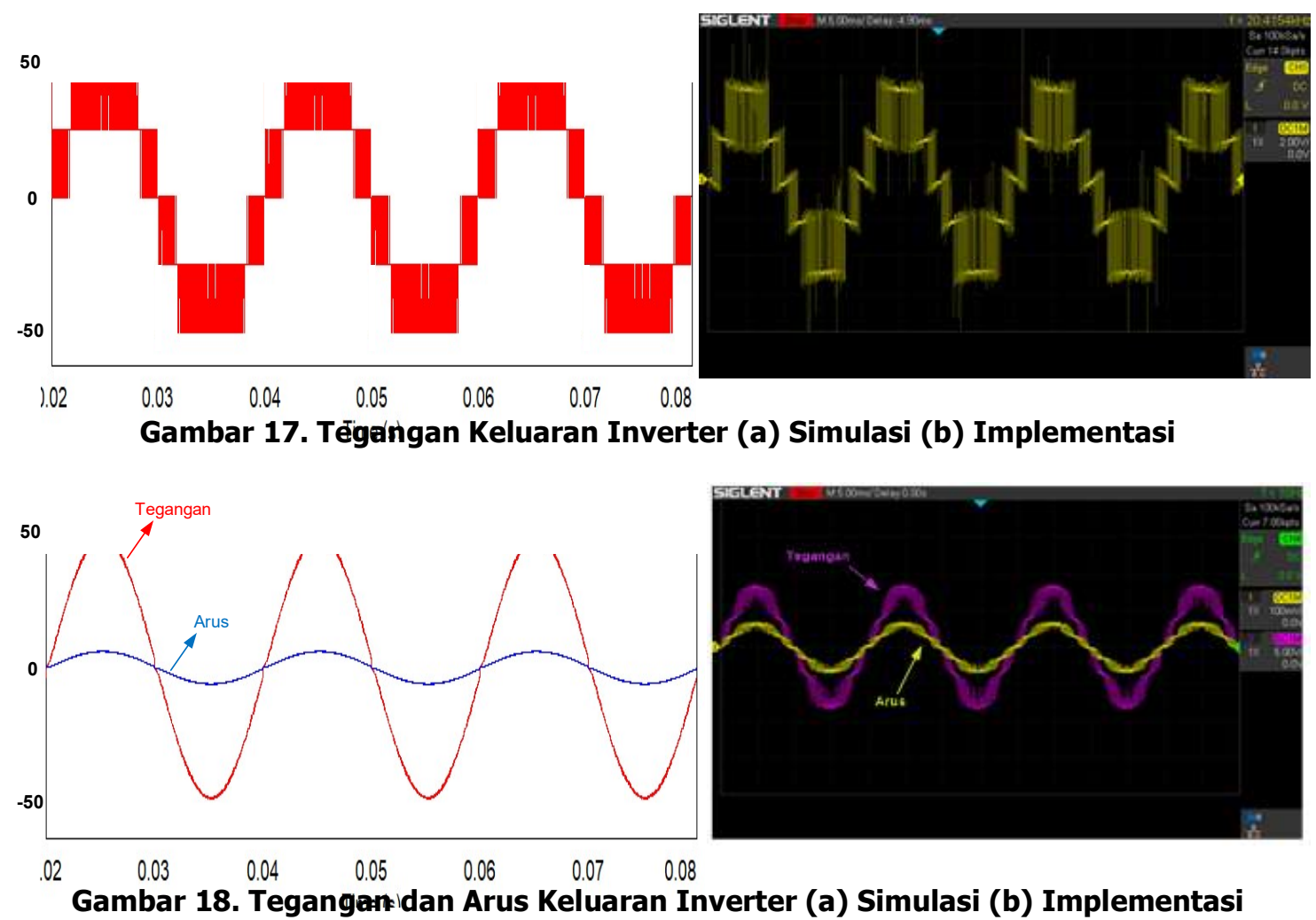

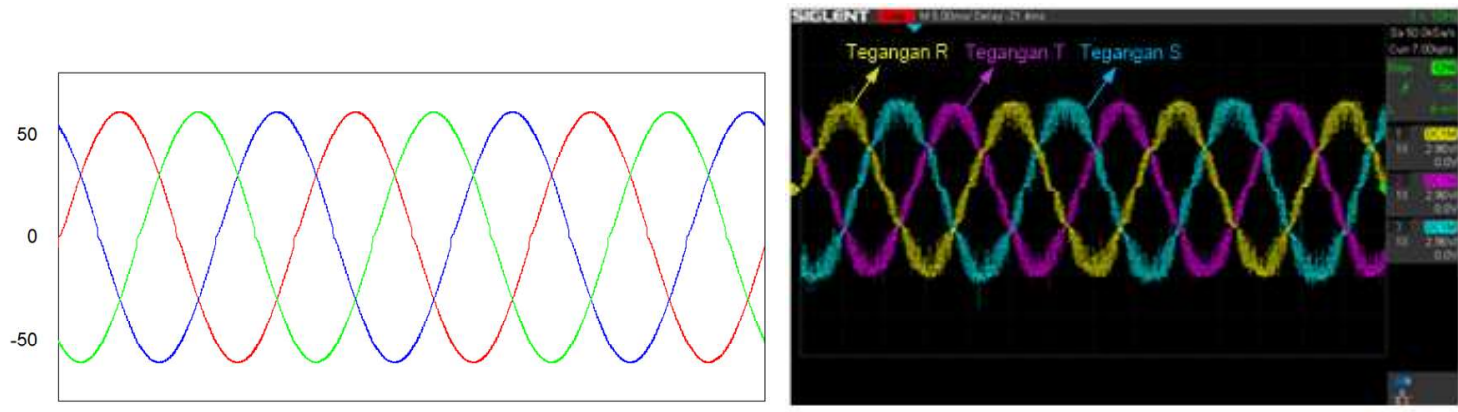

Gambar 19. Tegangan Keluaran Inverter 5-TFEK (a) Simulasi (b) Implementasi
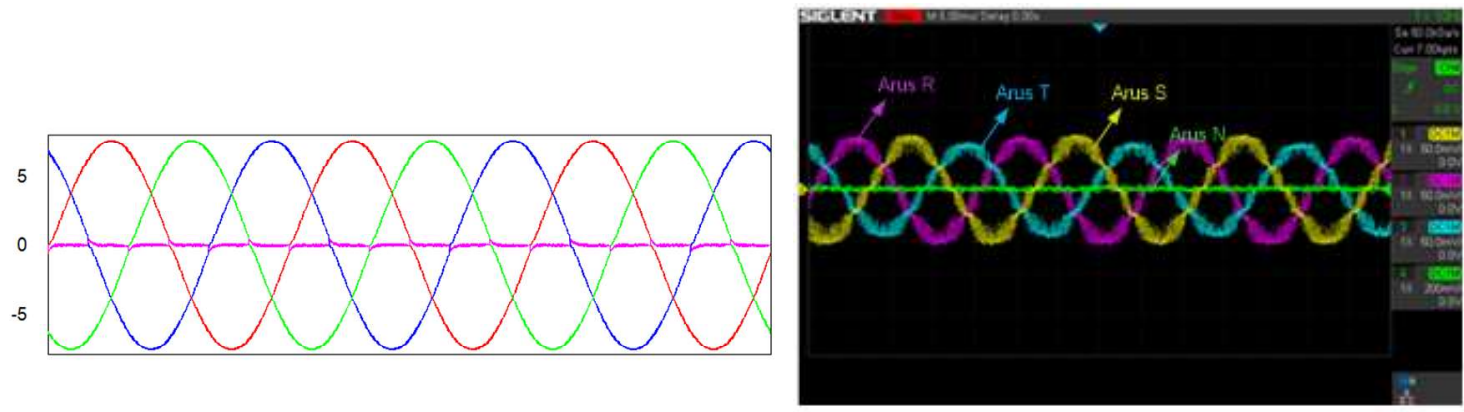

Gambar 20. Arus Keluaran Inverter 5-Tingkat TFEK (a) Simulasi (b) Implementasi

Tegangan keluaran inverter 5-Tingkat TFEK ditunjukkan seperti Gambar 19 (b). Gambar 20 (b). menunjukan arus keluaran tiap fasa dan arus netral. Nilai THD yang tinggi menyebabkan resiko rusaknya peralatan. Berdasarkan pengujian lebih lanjut, dapat dihasilkan nilai THD tegangan sebesar 4,38\%. Hasil pengujian ini sesuai dengan standart IEEE 519 sebesar dibawah $5 \%$.

\section{KESIMPULAN}

Berdasarkan analisi dan pengujian di laboratorium, algortima yang disarakan dapat membentuk keluaran inverter yang diinginkan. Dengan menggunakan MLPDS dapat menghasilkan arus dan tegangan keluaran inverter TFEK dengan frekuensi pensaklaran sebesar $5 \mathrm{KHz}$, dan tapis daya yang kecil menghasilkan nilai THD tegangan 4,38\%, menandakan sudah sesuai dengan standart IEEE 519 . Nilai THD yang tinggi menyebabkan resiko rusaknya peralatan. Oleh karena itu InverterTFEK sangat diasarankan untuk catu daya mandiri. Kelebihan menggunakan algoritma ini sakelar daya yang digunakan tidak mudah panas karena memiliki jeda waktu pergantian pensakelaran, sehingga rugi-rugi daya pada inverter berkurang dan kinerja inverter optimal.

\section{UCAPAN TERIMA KASIH}

Peneliti ini dibiayai oleh Kementrian Riset dan Teknologi/Badan Riset dan Inovasi Nasional Sesuai dengan Kontrak Penelitian Tahun Anggaran 2020. Dengan Nomor Adendum 010/LL6/PG/SP2H.1/AMD/PENELITIAN/2020. 


\section{DAFTAR RUJUKAN}

Aheshri, S., \& Khampariya, P. (2014). Simulation of Single Phase SPWM ( Unipolar ) Inverter. International Journal of Innovative Research in Advanced Engineering (IJIRAE), 1(9), $12-18$.

Ahmad, A., \& Maqbool, S. (2019). Square Wave Inverters - A Performance Comparison with Pure Sine Wave Inverters. International Journal Of Research in Electronics and Computer Engineering, 71$), 237-39$.

Algaddafi, A., Elnaddab, K., Al Ma'Mari A., \& Esgiar, A.N. (2017). Comparing the Performance of Bipolar and Unipolar Switching Frequency to Drive DC-AC Inverter. Proceedings of 2016 International Renewable and Sustainable Energy Conference, IRSEC 2016, (pp. 680-85).

Ardin, F., Rahardjo, A., \& Hudaya, C. (2017). Electricity Price and Subsidy Scenario for Hybrid Power Generations on Off-Grid System. ICCREC 2017 - 2017 International Conference on Control, Electronics, Renewable Energy, and Communications, (pp. 132-38).

IEEE Standards Association. (2014). IEEE Recommended Practice and Requirements for Harmonic Control in Electric Power Systems.

Hakim, A.R., Handoyo, W.T., \& Wullandari, P. (2018). An Energy and Exergy Analysis of Photovoltaic System in Bantul Regency, Indonesia Arif.

Hamid, N. F. A. I, Jalil, M.A.A., \& Mohamed, N.S.S. (2019). Design and Simulation of Single Phase Inverter Using SPWM Unipolar Technique. Journal of Physics: Conference Series 1432(1), 1-9.

Neukirchner, L., \& Magyar, A. (2017). Modelling a Three-Phase Current Source Inverter. Hungarian Journal of Industry and Chemistry, 44(2), 105-11.

Pratomo, L.H., \& Tjokro, C. (2019). Hardware Implementation of an Asymmetrical 11-Level Inverter with Automatic Boost Charge Control in PV Applications. Proceedings - 2019 International Seminar on Application for Technology of Information and Communication: Industry 4.0: Retrospect, Prospect, and Challenges, iSemantic 2019. (pp. 336-41).

Pratomo, L.H., Wijaya, F.D., \& Firmansyah, E. (2015). Capacitor Bank Voltage Equilibrium for MPPT in Single-Phase Single-Stage Capacitor Bank Voltage Equilibrium for MPPT in Single- Phase Single-Stage Five-Level Inverter for PV-Grid Application.

Pratomo, L.H., \& Riyadi, S. (2020). Desain Dan Implementasi Algoritma Korelasi Daya Dan Tegangan Di Kapasitor Untuk Maximum Power Point Trackking Pada Photovoltaic Menggunakan Arduino Uno. Jurnal Teknik Elektro, 12(1), 9-16. 
Inverter 5-Tingkat Tiga Fasa Empat Kawat Menggunakan STM32F407 untuk Catu Daya Mandiri

Rahman, T., Motakabber, S.M.A., \& Ibrahimy, M.I. (2016). Design of a Switching Mode Three Phase Inverter. Proceedings - 6th International Conference on Computer and Communication Engineering: Innovative Technologies to Serve Humanity, ICCCE 2016 (pp. 155-60).

Sanadeera, M, \& Miller, W. (2015). Residential Electricity Costs - Assessment Of Queensland Electricity Tariffs For Solar Households. IEEE PES Asia-Pacific Power Engineering Conference (APPEC), (pp. 6-9).

Tran, V.R., Nguyen, M.K., Yoo M.H., Choi, Y.O., \& Cho, G.B. (2017). A Three-Phase Cascaded H-Bridge Quasi Switched Boost Inverter for Renewable Energy. 2017 20th International Conference on Electrical Machines and Systems, ICEMS 2017.

Trivedi, J., Shah, M,. \& Shah, J. (2016). Three Phase 150 Degree Mode of Conduction Voltage Source Inverter Using Arduino. International Journal of Engineering Research And $5(12), 272-75$.

Wilson, A.O.M., \& Jiménez, J.B. (2016). Electricity Demand Modeling for Rural Residential Housing: A Case Study in Colombia. 2015 IEEE PES Innovative Smart Grid Technologies Latin America, ISGT LATAM 2015. Colombia: IEEE. (pp. 614-618). 